\title{
Resíduos de estações de tratamento de água e a ISO 24512: desafio do saneamento brasileiro
}

\author{
Residues of water treatment plants and ISO 24512: \\ challenge of the Brazilian sanitation
}

\begin{abstract}
Cali Laguna Achon
Engenheira Civil. Doutora em Engenharia Hidráulica e Saneamento pela Escola de Engenharia de São Carlos da Universidade de São Paulo (EESC/USP).

Pós-Doutoranda do Departamento de Engenharia Civil da Universidade Federal de São Carlos (DECiv/UFSCar) - São Carlos (SP), Brasil.

Marcelo Melo Barroso

Engenheiro Civil.Mestre e Doutor em Engenharia Hidráulica e Saneamento pela EESC/USP. Professor e Coordenador de Graduação do Curso de Engenharia de Inovação no Instituto Superior de Inovação e Tecnologia (ISITEC) - São Paulo (SP), Brasil.

\section{João Sérgio Cordeiro}

Engenheiro Civil. Mestre e Doutor em Engenharia Hidráulica e Saneamento pela EESC/USP. Ex-Presidente da Associação Brasileira de Ensino de Engenharia (ABENGE). Professor do Departamento de Engenharia Civil da Universidade Federal de São Carlos (DECiv/UFSCar) - São Carlos (SP), Brasil.
\end{abstract}

\section{Resumo}

O advento da ISO 24512:2007 suscita discussões muito interessantes em relação ao funcionamento dos sistemas de abastecimento de água em âmbito mundial. No Brasil, a maioria das estações de tratamento de água é convencional de ciclo completo, gerando resíduos complexos e de difícil manejo e disposição. Este trabalho teve como objetivo avaliar de forma crítica a problemática dos resíduos das estações de tratamento de água no Brasil, mediante o estudo da viabilidade de construção e uso de indicadores, tais como aqueles preconizados pela ISO 24512. A grande maioria das estações de tratamento de água analisadas, que refletem um quadro comum no Brasil, não dimensiona a quantidade de resíduos gerados, poucas avaliam suas características e destinam adequadamente esses resíduos, o que dificulta e, em muitos casos, pode impossibilitar o uso de indicadores como ferramentas de gestão. Esse cenário remete ao desafio enfrentado na área de saneamento em relação à gestão dos resíduos em consonância com as normas internacionais.

Palavras-chave: gestão; indicadores; ISO 24512; lodo; resíduos de estações de tratamento de água; tratamento de água.

\section{Abstract}

The advent of ISO 24512:2007 arouses some interesting discussions regarding the operation of water supply systems worldwide. In Brazil, the majority of water treatment plants is conventional, with a complete cycle, generating complex waste of difficult handling and disposal. This paper aimed at critically evaluating the problem of residues from water treatment plants in Brazil by studying the feasibility of construction and use of some indicators, such as those recommended by ISO 24512. The vast majority of water treatment plants analyzed, reflecting a common framework in Brazil, does not measure the amount of waste generated, few evaluate their features and dispose the residues properly, which makes it difficult and in many cases may preclude the use of indicators as management tools. This scenario brings to the challenge faced in the sanitation sector, regarding the management of residues in line with the international standards.

Keywords: management; indicators; ISO 24512; sludge; residues of water treatment plants; water treatment. 


\section{Introdução}

O advento das normas ISO 24510:2007, 24511:2007 e 24512:2007 suscitam discussões muito interessantes em relação ao funcionamento dos sistemas de saneamento a nível mundial. A série ISO 24510, desenvolvida pela Comissão Técnica ISO TC224 e publicada em dezembro de 2007, constitui o primeiro conjunto de normas de serviço publicadas pela International Organization for Standardization (ISO), que se caracteriza como sendo de aplicação voluntária, não se propondo a certificar.

Essa nova série de normas internacionais contém recomendações sobre as atividades relativas à gestão dos serviços de abastecimento de água e esgoto; contemplando três normas: ISO 24510 - "Activities relating to drinking water and wastewater service: guidelines for the assessment and for the improvement of the service to users"; ISO 24511 (2007b) - "Activities relating to drinking water and wastewater services: guidelines for the management of wastewater utilities and for the assessment of wastewater services"; e ISO 24512 - "Activities relating to drinking water and wastewater services: guidelines for the management of drinking water utilities and for the assessment of drinking water services".

A aplicação de tais normas tem grande importância na busca de melhoria de qualidade e sustentabilidade do setor de água e esgoto, caracterizando-se como ferramenta para o enquadramento na Lei 11.445/2007. Um dos aspectos fundamentais referentes ao aprimoramento da gestão de qualidade em sistemas de tratamento de água está intimamente ligado ao seu funcionamento, operação e características de geração e disposição final dos resíduos, que, na maioria das vezes, infringe as Leis 9.605/98 (BRASIL, 1998) e 11.445/2007 (BRASIL, 2007), exigindo dos gestores novas posturas. Assim, os indicadores propostos pela ISO 24512 se tornam ferramentas decisivas na avaliação e gestão dos sistemas, visando à melhoria contínua de qualidade.

No Brasil existem cerca de 7.500 estações de tratamento de água (ETAs) projetadas, em sua grande maioria, com ciclo completo, que inclui coagulação, floculação, decantação e filtração. Este sistema, como amplamente conhecido, gera resíduos, principalmente nos decantadores (lodo) e filtros, complexos em suas estruturas, pois possuem morfologia irregular, muitas vezes com características reológicas de fluido não newtoniano e ampla distribuição de tamanho de partículas (SLATTER, 1997; DENTEL, 1997), que são de difícil manejo e disposição. Há poucos estudos sobre o tema no Brasil e, consequentemente, as soluções para a adequada gestão deste resíduo raramente são adotadas em ETAs em funcionamento. Apesar de algumas iniciativas, a maioria das novas estações também negligencia a gestão do lodo.

A maioria das ETAs lança seus resíduos em cursos d'água, contrariando a legislação vigente e provocando impactos ambientais. As operadoras responsáveis pelos sistemas de tratamento de água precisam estar cientes da sua responsabilidade ambiental, pois a matéria-prima pode estar cada vez mais com a qualidade comprometida. Os novos projetos de ETAs devem estar plenamente adequados à legislação. Dessa forma, os cuidados ambientais devem ser mais amplos do que aqueles até hoje adotados e empreendidos pelos sistemas de tratamento. Para isso, existem alternativas legais para o licenciamento de ETAs sem a disposição adequada de lodo em alguns estados, desde que obedeçam aos prazos para a solução do problema definidos na legislação, dentro do princípio de metas progressivas. Além disso, para ETAs de pequeno porte, em muitas situações, o licenciamento é dispensado, caso os impactos ambientais sejam considerados não significantes.

Este trabalho teve como objetivo geral avaliar de forma crítica a problemática dos resíduos de ETAs no Brasil, mediante o estudo da viabilidade de construção e uso de indicadores, tais como os preconizados pela ISO 24512. O objetivo específico foi verificar a potencialidade do uso de indicadores de maneira a permitir avaliar a qualidade da gestão de resíduos em ETAs.

\section{Resíduos de estações de tratamento de água no Brasil}

No processo de produção de água potável, considerado como uma das etapas da indústria da água, há geração de resíduos devido à presença de impurezas na água bruta e aplicação de produtos químicos. Esses resíduos apresentam características e propriedades diversas e geralmente desconhecidas, dificultando a solução do problema.

Os principais resíduos gerados nas ETAs, que possuem tecnologia de ciclo completo, são o lodo de decantadores e a água de lavagem de filtros (ALAF). As principais perdas de água, neste tipo de sistema, ocorrem devido à necessidade de limpeza das unidades de tratamento para remoção de resíduos (lavagem de floculadores, decantadores e filtros) e vazamentos nas unidades e/ou tubulações. O lodo é definido como resíduo sólido, e, portanto, deve estar em consonância com os preceitos da Lei 12.305/2010 (artigo 3 ${ }^{\circ}$, inciso XVI) (BRASIL, 2010) e da série de normas NBR 10.004/2004 (ABNT, 2004).

No Brasil, a implantação de sistemas de tratamento de água está sujeita ao licenciamento ambiental, conforme a Resolução 237 de 19 de dezembro de 1997 do Conselho Nacional de Meio Ambiente (Conama) (BRASIL, 1997b). Esta é uma obra de utilidade pública causadora de impactos ambientais negativos, com o lançamento de resíduos provenientes dos decantadores e da ALAF em corpos d'água. A Política Nacional de Recursos Hídricos - PNRH (Lei 9.433/97) estabelece que

o lançamento de resíduos líquidos, sólidos ou gasosos, tratados ou não, com o fim de sua diluição, transporte ou disposição final em corpos d'água, além de outros usos que alterem o regime, a quantidade ou a qualidade da água, está sujeita à outorga do Poder Público (BRASIL, 1997a). 
O lançamento em corpos d'água dos resíduos gerados em ETAs, quando não aprovado por órgãos ambientais, pode ser considerado crime ambiental devido aos efeitos diretos causados ao ambiente aquático do corpo receptor, provocando danos à fauna aquática. Constitui-se crime ambiental, de acordo com o artigo 54 da Lei 9.605/98.

Com os fundamentos da PNRH e baseado na Lei de Crimes Ambientais, são relevantes as questões do lançamento e da disposição final dos resíduos sólidos gerados em ETAs, na gestão ambiental integrada entre "água e solo".

Quanto às características, alguns trabalhos têm mostrado que a concentração de metais nos resíduos das ETAs pode ultrapassar limites impostos pelo padrão de emissão (CORDEIRO, 1993; 2001; BARROSO \& CORDEIRO, 2002). Isso pode influenciar a qualidade da água tratada e comprometer ainda mais as condições de lançamento do lodo em corpos d'água. Portanto, os gestores responsáveis por sistemas que lançam resíduos in natura nos corpos d'água devem iniciar ações que permitam avaliar a forma de geração e destino dos mesmos e definir estratégias para essa solução.

A forma de remoção de lodo das ETAs pode ser considerada um dos principais problemas de gestão deste resíduo, pois influencia diretamente em sua quantidade e qualidade.

No Brasil, a frequência de remoção de lodo nos decantadores de ETA convencional de ciclo completo pode ser realizada em intervalos de até seis meses, pode gerar acúmulo de lodo com elevada concentração de contaminantes orgânicos e inorgânicos e também pode dificultar a remoção e disposição final. Assim, em algumas ETAs, é necessária a utilização de água em alta pressão a fim de auxiliar a remoção do lodo e raspadores manuais (rodos de madeira), que implica no contato direto de funcionários com este resíduo (ACHON, 2008).

Cornwell et al. (2000) realizaram um levantamento sobre as formas de disposição final de lodos das ETAs nos Estados Unidos. Tais pesquisadores verificaram que $25 \%$ das ETAs aplicam o lodo no solo, 24\% lançam-no em sistemas públicos de esgotos, 20\% dispõem-no em aterro, 13\% em aterro exclusivo e $7 \%$ realizam outras formas de disposição final. Apenas 11\% das ETAs lança o lodo nos corpos d'água.

Segundo Simpson et al. (2002), no Reino Unido, apenas 2\% das ETAs lançam o lodo nos corpos d'água e há uma predominância de disposição final em aterros sanitários (52\%), seguida de 29\% que lançam-no em sistemas públicos de esgoto, 9\% têm novos métodos, $6 \%$ realizam tal processo em aterro exclusivo e $2 \%$ em lagoas.

No Brasil, este quadro é bem diferente. Segundo Cordeiro (1993) e Morita et al. (2002), a maioria das ETAs do estado de São Paulo lança os lodos gerados nos decantadores em corpos d'água mais próximos sem tratamento prévio, causando problemas ambientais.

No Estado de Minas Gerais foram coletadas informações de 175 municípios, mostrando que 87\% das ETAs dos municípios mineiros avaliados lançam o lodo em corpos d'água sem tratamento, $6 \%$ não informaram, 3\% possuem unidades de tratamento de resíduos (UTR), 2\% lançam na rede pluvial, 1\% em ETE e 1\% no solo (MINISTÉRIO PÚBLICO DO ESTADO DE MINAS GERAIS, 2009).

No Estado de São Paulo, levantamentos preliminares realizados na Bacia PCJ (Piracicaba, Capivari e Jundiaí) indicaram que 56\% (em termos populacionais) lançam o lodo de ETA em corpos d'água, 21\% em aterro, 15\% não disponibilizaram dados, 6\% em ETEs e 1\% em outros locais (PCJ, 2011)

Tradicionalmente, no Brasil, a maior e mais importante preocupação, ainda que incipiente, tem sido em relação aos resíduos gerados em estações de tratamento de esgotos, que também deveria se refletir para os resíduos gerados em ETAs. Por outro lado, o desenvolvimento tecnológico do tema tem esbarrado em replicar tecnologias importadas, em pesquisas desarticuladas e soluções empíricas localizadas. Esse desenvolvimento muitas vezes é incentivado por mudanças e cobranças nos campos normativo e legal.

Inúmeros direcionamentos foram elaborados quanto aos aspectos qualitativos, quantitativos e de técnicas para redução de água no resíduo. No entanto, correspondem, ainda, a ações desarticuladas entre os diversos institutos de pesquisas e, principalmente, com dificuldade quanto à transferência de tecnologia para empresas, municípios e estados. Salvo iniciativas como o Programa de Pesquisas em Saneamento Básico - Prosab (REALI, 1999; ANDREOLI, 2001) e, mais recentemente, em 2008, com a realização do Seminário Nacional sobre Tratamento, Disposição e Usos Benéficos de Lodos de ETAs, que concluiu:

ainda hoje a maioria das ETAs lança diretamente seus lodos nos corpos d'água mais próximos; o setor de saneamento ambiental precisa ter uma visão mais abrangente do sistema de tratamento de água. Atualmente ela é horizontal [...]; há tendência internacional em se reduzir a quantidade de lodo produzido nas ETAs; o restante deve ser reciclado ou reusado e somente o que não puder ser aproveitado deve ser disposto (IE/SP, 2008).

\section{ISO 24512:2007}

A ISO é uma federação mundial integrada por organismos nacionais de normalização em cada país. Sua missão é promover o desenvolvimento de tal operação no mundo, com os objetivos de facilitar a troca internacional de mercadorias e serviços e desenvolver a cooperação nas esferas das atividades econômicas tecnológicas e científicas.

A discussão sobre esta nova série de normas ISO 24510 iniciou-se em setembro de 2002, na França, após a criação do Comitê Técnico (TC 224) em 2001, onde se realizou a primeira plenária com participação de 33 países e algumas organizações internacionais, tais como: Associação Interamericana de Engenharia Sanitária e Ambiental 
(AIDIS); African Water Association (AfWA); Consumers International (CI), European Union of National Associations of Water Suppliers and Waste Water Services (EUREAU); International Water Association (IWA); European Office of Crafts, Trades and Small and Medium-Sized Enterprises for Standardisation (NORMAPME); World Health Organization (WHO); e World Bank Group Archives (WBGA) (ISO, 2007d).

Os países da América que participam do comitê técnico 224 são: Argentina, Canadá, Cuba, Estados Unidos, México e Uruguai. A Colômbia e o Equador são apenas países observadores, e o Brasil não faz parte (ISO, 2007d).

A nova série de normas ISO 24510, publicada em dezembro de 2007 em inglês e francês, pretendeu desenvolver padrões internacionais para a gestão de atividades e serviços relacionados com os sistemas de abastecimento de água e esgotamento sanitário. São normas de utilização voluntária e não se propõem a certificar. A tradução para o português foi iniciada em 2011 e está sendo elaborada pela Associação Brasileira de Normas Técnicas/Comissão de Estudos Especiais de Serviços de Abastecimento de Água e de Esgotamento Sanitário (ABNT/CEE 166). A série ISO 24510 (ISO, 2007a) é composta pelas normas:

- ISO 24510 - "Activities relating to drinking water and wastewater services: guidelines for the assessment and for the improvement of the service to users";

- ISO 24511 - "Activities relating to drinking water and wastewater services: guidelines for the management of wastewater utilities and for the assessment of wastewater services";

- ISO 24512 - "Activities relating to drinking water and wastewater services: guidelines for the management of drinking water utilities and for the assessment of drinking water services".

A norma ISO 24512 (ISO, 2007c) define seis objetivos principais do sistema de abastecimento de água, conforme descritos a seguir:

- proteção da saúde pública: referente à qualidade, potabilidade e suficiência do abastecimento de água;

- satisfação das necessidades e expectativas dos usuários: contemplado na ISO 24510;

- prestação de serviços em situações normais e de emergência: abastecimento contínuo, pressão adequada e confiabilidade;

- sustentabilidade do prestador de serviços: capacidade de tratamento, de reservação, de transmissão e do sistema de distribuição, dos recursos hídricos, força de trabalho e estruturas tarifárias;

- promoção do desenvolvimento sustentável na comunidade: gestão dos recursos hídricos (proteção dos mananciais), redução da geração de resíduos e uso sustentável dos insumos;

- proteção do meio ambiente: perdas de água, energia e gestão de resíduos.

A ISO 24512 preconiza o uso dos indicadores de desempenho (ALEGRE et al., 2006) como instrumento principal para auxiliar a gestão dos serviços de abastecimento de água, e exemplifica alguns para cada um dos seis objetivos citados.

Os resíduos estão inseridos nos indicadores que objetivam a proteção do meio ambiente, sendo a reciclagem do lodo um dos exemplificados na ISO 24512, que indica a porcentagem daquele reciclado em relação ao total de lodo gerado durante o tratamento da água.

Vieira et al. (2009) propuseram um sistema de indicadores de desempenho (PAS - Performance Assessment Systems) para avaliar as ETAs em Portugal, e confirmaram a aplicabilidade deste sistema em um estudo de caso em quatro ETAs, cujo período de estudo foi de 2001 a 2007. No entanto, segundo os autores, ainda é necessário reforçar a aplicabilidade de tal sistema em ETAs com diferentes tipologias e estabelecer valores de referência para as medidas de desempenhos global e operacional.

\section{Metodologia}

A ISO 24512:2007 recomenda o uso de indicadores de desempenho entre os vários instrumentos de avaliação existentes. De acordo com a ISO 24512, eles devem ser utilizados no contexto de um sistema abrangente de avaliação, devendo ser adequados para representar os aspectos relevantes do serviço. Os indicadores de desempenho são tipicamente expressos como relação entre variáveis, permitindo comparações ao longo do tempo ou entre sistemas. As variáveis podem ser dados gerados internamente ou externamente pelo sistema. Porém, a ISO 24512 apenas exemplifica alguns, sendo que os demais indicadores devem ser criados pelo próprio sistema de abastecimento de água.

No Quadro 1, apresentam-se os dois indicadores exemplificados na norma ISO 24512, referente aos resíduos de ETAs. De acordo com esta norma, esses indicadores avaliam a proteção ambiental dos sistemas, referente à gestão de resíduos.

Além da aplicação dos dois indicadores exemplificados pela ISO 24512 e apresentados no Quadro 1, buscou-se propor e aplicar outros, definidos a partir da seguinte metodologia.

Primeiramente, foram selecionadas cinco ETAs localizadas no Estado de São Paulo para fazer parte da pesquisa (A, B, C, D e E). As estações escolhidas possuem tecnologia de tratamento de ciclo completo e refletem um quadro atual e comum no Brasil.

\section{Quadro 1 - Indicadores exemplificados na norma ISO 24512 para analise} de resíduos.

\begin{tabular}{|ccc|}
\hline & Indicador & Unidade \\
\hline 1 & $\begin{array}{c}\text { Porcentagem do lodo reutilizado } \\
\text { ou reciclado após tratamento. }\end{array}$ & $\%$ \\
\hline 2 & $\begin{array}{c}\text { Porcentagem da água de lavagem de filtros } \\
\text { reutilizada ou reciclada após tratamento. }\end{array}$ & $\%$ \\
\hline
\end{tabular}

Fonte: ISO 24512 (2007c) 
Foram estudadas legislação, normas e indicadores, por meio de levantamento bibliográfico. Em seguida, realizaram-se visitas preliminares às cinco ETAs selecionadas, a fim de analisar seu funcionamento in loco.

Com o embasamento teórico proporcionado durante a fase inicial e as visitas preliminares, elaborou-se um formulário para diagnóstico e coleta de dados. Foram realizadas novas visitas para levantamento de dados, por meio de entrevistas com os gerentes e/ou responsáveis pela estação, consulta a arquivos digitais, relatórios e anotações manuais em planilhas de controle operacional e verificação operacional.

Após esta fase, os dados foram analisados e sistematizados, o que convergiu para seleção de variáveis e elaboração de indicadores, relacionados aos resíduos de decantadores (lodo) e filtros (ALAF). No Quadro 2 são apresentados os sete indicadores elaborados e propostos.

Os dois indicadores exemplificados pela ISO 24512 (Quadro 1) e os sete propostos (Quadro 2) foram aplicados nas cinco ETAs analisadas. Esses nove indicadores podem ser utilizados para análise geral dos resíduos gerados em cada ETA e também extrapolados para análise comparativa de diferentes ETAs.

A análise dos resultados e as discussões culminaram nas considerações finais apresentadas neste artigo.

Quadro 2 - Indicadores propostos para análise de resíduos de decantadores e filtros.

\begin{tabular}{|c|c|c|}
\hline Item & Indicador & Unidade \\
\hline 1 & $\begin{array}{l}\text { Tipo de água utilizada na lavagem de decan- } \\
\text { tadores e filtros (tratada, decantada ou bruta). }\end{array}$ & 1,2 ou $3^{*}$ \\
\hline 2 & $\begin{array}{l}\text { Volume de lodo gerado nos decantadores em } \\
\text { litros por volume de água tratada. }\end{array}$ & L.m $\mathrm{m}^{-3}$ \\
\hline 3 & $\begin{array}{c}\text { Volume de lodo gerado nos decantadores } \\
\text { pela área total dos decantadores. }\end{array}$ & $\mathrm{m}^{3} \cdot \mathrm{m}^{-2}$ \\
\hline 4 & $\begin{array}{l}\text { Volume de ALAF gerada em litros } \\
\text { por volume de água tratada. }\end{array}$ & L.m $\mathrm{m}^{-3}$ \\
\hline 5 & $\begin{array}{l}\text { Volume de ALAF gerada por } \\
\text { área total dos filtros. }\end{array}$ & $\mathrm{m}^{3} \cdot \mathrm{m}^{-2}$ \\
\hline 6 & Tratamento do lodo e da ALAF. & 1,2 ou $3^{\star *}$ \\
\hline 7 & $\begin{array}{c}\text { Perda de água nas lavagens: volume de água } \\
\text { utilizado na lavagem de decantadores e filtros } \\
\text { por volume de água tratada. }\end{array}$ & $\begin{array}{c}\% \text { e } \\
\mathrm{m}^{3} \cdot \mathrm{hab}^{-1} \cdot \mathrm{ano}^{-1}\end{array}$ \\
\hline
\end{tabular}

*1: água tratada; 2: água decantada; 3: água bruta. **1: tratamento inexistente; 2: tratamento parcial; 3: tratamento total. ALAF: água de lavagem de filtros. Fonte: Achon (2008)

\section{Resultados}

Na Tabela 1 são apresentados os dados gerais das cinco ETAs analisadas.

A seguir, serão mostradas as aplicações dos indicadores exemplificados pela Norma ISO 24512 e aqueles propostos, conforme descritos na metodologia (Quadro 1 e 2).

\section{Indicadores exemplificados na ISO 24512 para análise da gestão dos resíduos}

O indicador de porcentagem do lodo reutilizado ou reciclado após tratamento é 0\% para as cinco ETAs.

$\mathrm{O}$ indicador de porcentagem da ALAF reutilizada ou reciclada após tratamento para as ETAs A, B e E é 0\%, para a C é 51,25\% e para a D é maior que $0 \%$. No entanto, o volume de água recuperada não é medido, o que impossibilita a aplicação correta deste indicador para a ETA D.

\section{Aplicação dos indicadores propostos para análise dos resíduos de ETAs}

$\mathrm{Na}$ Tabela 2 podem ser vistos os resultados dos indicadores relacionados ao tipo de água utilizada na lavagem de decantadores e filtros para as cinco ETAs.

Os indicadores apresentados na Tabela 2 mostram que apenas as ETAs C e D utilizam água decantada para lavar os decantadores e todas utilizam água tratada, após coagulação e desinfecção, para os filtros. Isso resulta em perdas não só de água, como de produtos químicos e energia elétrica intrínseca.

Tabela 2 - Indicadores relacionados ao tipo de água utilizada na lavagem de decantadores e filtros.

\begin{tabular}{ccc} 
ETA & $\begin{array}{c}\text { Tipo de água utilizada na } \\
\text { lavagem dos decantadores }\end{array}$ & $\begin{array}{c}\text { Tipo de água utilizada na } \\
\text { lavagem dos filtros }\end{array}$ \\
\hline A & 1 & 1 \\
B & 1 & 1 \\
C & 2 & 1 \\
D & 2 & 1 \\
E & 1 & 1 \\
\hline
\end{tabular}

Indicador 1: utiliza água tratada para lavagem (após coagulação e desinfecção); Indicador 2: utiliza água decantada para lavagem (após coagulação); Indicador 3: utiliza água bruta para lavagem (anterior à coagulação).

Tabela 1 - Dados gerais das cinco estações de tratamento de águas (ETAs) analisadas.

\begin{tabular}{|c|c|c|c|c|}
\hline ETA & Tipo de administração & População abastecida & $\begin{array}{l}\text { Vazão média anual de operação } \\
\left(\text { L.s }^{-1}\right)\end{array}$ & Coagulante utilizado \\
\hline$A$ & Autarquia municipal & 79.000 & 359 & Cloreto férrico \\
\hline B & Privada & 260.000 & 675 & Sulfato de alumínio \\
\hline $\mathrm{C}$ & Autarquia municipal & 240.000 & 1.135 & Sulfato de alumínio \\
\hline $\mathrm{D}$ & Autarquia municipal & 112.200 & 411 & Cloreto férrico \\
\hline$E$ & Autarquia municipal & 90.000 & 426 & Sulfato de alumínio \\
\hline
\end{tabular}


A Tabela 3 demonstra os indicadores de volume anual de lodo gerado nos decantadores por volume de água tratada em L.m ${ }^{-3}$ por área total dos decantadores $\mathrm{em}^{3} \cdot \mathrm{m}^{-2}$, e aqueles de ALAF por volume de água tratada em L. $\mathrm{m}^{-3}$ e por área total dos filtros $\mathrm{em}^{3} \cdot \mathrm{m}^{-2}$ para as cinco ETAs analisadas.

Conforme apresentado na Tabela 3, o indicador de volume de lodo em L.m ${ }^{-3}$ na ETA A é praticamente igual ao da C, aproxima-

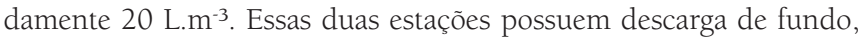
apesar do decantador da ETA C ser convencional com fundo plano (raspadores por sucção) e o da A, de alta taxa.

$O$ indicador de $\mathrm{m}^{3} \cdot \mathrm{m}^{-2}$ de área do decantador, apresentado na segunda coluna da Tabela 3, para a ETA A é o dobro da C. Porém, este pode provocar equívocos na interpretação dos resultados, visto que, normalmente, o decantador de alta taxa requer menor área de implantação. Assim, o indicador de volume de lodo $\mathrm{em}^{3} \cdot \mathrm{m}^{-2}$ não é o mais apropriado quando são analisados decantadores com diferentes tecnologias, porém serve para avaliação histórica comparativa da mesma ETA ou entre decantadores de mesma concepção.

O indicador de ALAF em L.m $\mathrm{m}^{-3}$, apresentado na terceira coluna da Tabela 3, para a ETA C, é 26\% da A. Porém, aquele apresentado na quarta coluna, em $\mathrm{m}^{3} \cdot \mathrm{m}^{-2}$, para a ETA C é $83 \%$ do A, ou seja, valores mais próximos, podendo representar um indicador mais adequado quando se compara o volume de ALAF em diferentes sistemas.

Comparando os indicadores das primeira e terceira colunas da Tabela 3, para a ETA C o volume de resíduos gerados nos decantadores, em L.m³ , é $67 \%$ do gerado nos filtros, enquanto que, para a A, isto se inverte, o volume de lodo é $271 \%$ da ALAF. Desse modo, nem sempre o volume de resíduos gerados nos filtros pode ser a parcela mais representativa do volume total de resíduos gerados em estações convencionais de ciclo completo.

Os indicadores de tratamento de lodo e ALAF para as cinco estações são apresentados na Tabela 4, os quais também representam, implicitamente, a porcentagem de resíduos que não é lançada in natura nos corpos d'água.

Os indicadores apresentados na Tabela 4 refletem a ausência de tratamento de lodo e não recuperação da ALAF, na grande maioria das ETAs analisadas.

Os indicadores relacionados ao volume de água descartado durante as lavagens de decantadores e filtros e volume de água perdido anualmente na ETA, em relação ao volume de água tratada e a população abastecida, encontram-se na Tabela 5.

A Tabela 5 apresenta dois tipos de indicadores de perdas de água, o primeiro expresso em porcentagem em relação ao volume de água aduzido e o outro referente à população abastecida pela ETA, o que pode representar indicadores de comparação. $\mathrm{O}$ indicador de perdas de água em $\mathrm{m}^{3}$.hab ${ }^{-1}$.ano-1 , apresentado na terceira coluna da Tabela 5 , é maior que $5 \%$ em quatro sistemas e, para apenas um, é cerca de $2 \%$.

Este estudo não teve por objetivo selecionar indicadores, pois cada sistema pode adotar aqueles que se adaptem melhor à sua realidade.

\section{Considerações finais}

No Brasil, a problemática dos resíduos de ETAs deve ser analisada sob a ótica da legislação vigente, levando-se em conta aspectos relativos ao conhecimento mais profundo sobre as características físicas, químicas e biológicas; as condições operacionais dos sistemas de tratamento de água que geram esses resíduos; as condições e periodicidade de limpeza de filtros e decantadores; os impactos ambientais do lançamento in natura (solo ou águas superficiais); as alternativas de tratamento dos resíduos e a destinação ou disposição final das fases sólida e líquida após o tratamento (desaguamento).

Avaliar e gerenciar as unidades de tratamento em uma ETA podem ser úteis também para minimizar a água utilizada na limpeza das unidades e, consequentemente, reduzir a geração de resíduos. Adotar sistemas mais eficientes, que busquem economia na água de lavagem dos decantadores e filtros, deve ser considerado no projeto e nos procedimentos operacionais de um sistema de tratamento de água.

Tabela 4 - Indicadores de tratamento de lodo e água de lavagem de filtros (ALAF).

\begin{tabular}{ccc} 
ETA & Lodo tratado & ALAF tratada \\
A & 1 & 1 \\
B & 1 & 1 \\
C & 1 & 2 \\
D & 3 & 3 \\
E & 1 & 1 \\
\hline
\end{tabular}

Indicador 1: o volume gerado não é tratado; Indicador 2: o volume gerado é parcialmente tratado; Indicador 3: o volume gerado é tratado.

Tabela 3 - Indicadores de volume de lodo gerado nos decantadores e de ALAF.

\begin{tabular}{|c|c|c|c|c|}
\hline ETA & $\begin{array}{l}\text { Volume de lodo gerado nos de- } \\
\text { cantadores por volume de água } \\
\text { tratada }\left(\mathrm{L} \cdot \mathrm{m}^{-3}\right)\end{array}$ & $\begin{array}{l}\text { Volume anual de lodo gerado } \\
\text { nos decantadores pela área total } \\
\text { dos decantadores }\left(\mathrm{m}^{3} \cdot \mathrm{m}^{-2}\right)\end{array}$ & $\begin{array}{l}\text { Volume de ALAF gerada por } \\
\text { metro cúbico de água tratada } \\
\left(\text { L. }^{-3}\right)\end{array}$ & $\begin{array}{l}\text { Volume anual de ALAF gerada } \\
\text { por área total dos filtros }\left(\mathrm{m}^{3} \cdot \mathrm{m}^{-2}\right)\end{array}$ \\
\hline A & 20,51 & 750,15 & 30,36 & $1.603,33$ \\
\hline C & 21,72 & 372,26 & 8,00 & $1.331,37$ \\
\hline D & Não é medido & Não é medido & Não é medido ${ }^{1}$ & Não é medido ${ }^{1}$ \\
\hline
\end{tabular}

1estimado em $6 \%$ do volume tratado; ${ }^{2}$ estimado em $5 \%$ do volume tratado. 
Tabela 5 - Indicadores de perdas de água nas lavagens de decantadores e filtro e na estação de tratamento de água (ETA), em relação ao volume de água tratada e população abastecida.

\begin{tabular}{|c|c|c|c|}
\hline ETA & $\begin{array}{c}\text { Perda de água nas lavagens: volume de } \\
\text { água descartado }{ }^{1} \text { por volume de água } \\
\text { tratada (\%) }\end{array}$ & $\begin{array}{l}\text { Perda de água na ETA em porcentagem: } \\
\text { volume de água perdido }{ }^{2} \text { na ETA por volume } \\
\text { de água tratada } \\
(\%)\end{array}$ & $\begin{array}{c}\text { Perda de água na ETA por habitante: volume } \\
\text { de água perdido na ETA pela população } \\
\text { abastecida }\left(\mathrm{m}^{3} \cdot \mathrm{hab}^{-1} \cdot \mathrm{ano}^{-1}\right)\end{array}$ \\
\hline A & 5,09 & $5,09^{3}$ & 7,18 \\
\hline B & Não é medido & 2,64 & 2,13 \\
\hline $\mathrm{C}$ & 2,97 & $3,12^{4}$ & 5,27 \\
\hline $\mathrm{D}$ & Não é medido. Estimado em $6 \%$ & Não é medido & $6,95^{5}$ \\
\hline$E$ & Não é medido. Estimado em 5\% & Não é medido & $7,50^{5}$ \\
\hline
\end{tabular}

${ }^{1}$ volume descartado = volume de água utilizado na lavagem de decantadores e filtros, durante a remoção de lodo (descargas de fundo de decantadores) e antes da lavagem dos decantadores (volume das unidades - flutuadores e decantadores); ${ }^{2}$ volume perdido = diferença entre o volume medido na saída e na entrada da ETA; ${ }^{3} a$ ETA A não mede o volume perdido; porém, considera-se aquele descartado como o total perdido na ETA; ${ }^{4}$ a ETA C não mede o volume perdido; no entanto, considera como perdas de água aquele descartado mais o de água consumido internamente na ETA, menos o volume de ALAF recuperado; ${ }^{5}$ para aplicação deste indicador nas ETAs D e E, considerou-se apenas o volume descartado, que é estimado.

Deve-se analisar também o projeto dos decantadores, bem como o formato, as dimensões e a facilidade de remoção do lodo, que, na maioria das ETAs convencionais, não são viáveis. Os decantadores laminares (alta taxa), por exemplo, são lavados com mais frequência, porém consomem menos quantidade de água durante a lavagem.

Neste trabalho, ao se propor a obtenção de indicadores que viabilizassem a gestão de resíduos de ETAs, explicitou-se a dificuldade em se obter dados e, consequentemente, indicadores das ETAs estudadas. Concorreu para isso a constatação de que a grande maioria das ETAs não mede a quantidade de resíduos gerados e muito menos avalia suas características. Tal fato mostra-se agravante se considerarmos que as ETAs em estudo possuem características de sistemas de médio porte e estão localizadas em municípios com boa estrutura, acima da média das cidades brasileiras.

Assim, as dificuldades encontradas na obtenção dos indicadores de gestão de lodo reportadas neste trabalho podem refletir, em grande medida, os desafios que os gestores dos sistemas de tratamento de água terão ao buscar a conformidade das ETAs brasileiras, baseadas nas diretrizes preconizadas pela ISO 24512.

Esse cenário remete aos desafios do século XXI na área de saneamento, particularmente nas ETAs, em relação à gestão de seus resíduos, de acordo com os preceitos das normas internacionais. Esses resíduos precisam ser gerenciados com uma nova visão: sistêmica e ampliada.

Quando se analisa o funcionamento das ETAs para abastecimento público no Brasil, principalmente quanto à forma de geração e disposição dos resíduos gerados nos decantadores e filtros, faz-se necessário uma discussão mais profunda para que a cultura de gestão de qualidade se torne uma prática nas ETAs.

\section{Agradecimentos}

À Fundação de Amparo à pesquisa do Estado de São Paulo (Fapesp).

\section{Referências}

ABNT - Associação Brasileira de Normas Técnicas. (2004) NBR 10.004: 2004. Rio de Janeiro, 48 p.

ACHON, C.L. (2008) Ecoeficiência de sistemas de tratamento de água a luz dos conceitos da ISO 14.001. Tese (Doutorado) - Escola de Engenharia de São Carlos, Universidade de São Paulo, São Carlos, $230 \mathrm{p}$

ALEGRE, H.; BAPTISTA, J.M.; CABRERA JR., E.; CUBILLO, F.; DUARTE, P.; HIRNER, W.; MERKEL, W.; PARENA, R. (2006) IWA Performance Indicators for Water Supply Services. Manual of Best Practice Series Second Edition. London: IWA Publishing, ISBN 1843390515, 305 p.

ANDREOLI, C.V. (2001) Resíduos sólidos do saneamento: processamento, reciclagem e disposição final. Projeto PROSAB 2. Rio de Janeiro: RiMa, ABES, $282 \mathrm{p}$.
BARROSO, M.M. \& CORDEIRO, J.S. (2002) Problemática dos metais nos resíduos gerados em estações de tratamento de águas. In: Anais do $21^{\circ}$ Congresso Brasileiro de Engenharia Sanitária e Ambiental, ABES, cd, I-065.

BRASIL. (1997a) Lei 9.433 de 8 de Janeiro de 1997. Política Naciona dos Recursos Hídricos. Diário Oficial da União, Brasília, DF

BRASIL. (1997b) Resolução CONAMA No 237 de 19 de dezembro de 1997. Procedimentos e critérios utilizados no licenciamento ambiental como instrumento de gestão ambiental. Brasil: Ministério do Meio Ambiente.

BRASIL. (1998) Lei 9.605. Lei da Vida - A lei dos Crimes Ambientais. Diário Oficial da União, Brasília, DF.

BRASIL. (2007) Lei 11.445 de 05 de janeiro de 2007. Política Nacional do Saneamento Básico. Brasília, DF: Congresso Nacional. 
BRASIL. (2010) Lei 12.305 de 02 de agosto de 2010. Política Nacional de Resíduos Sólidos. Brasília, DF: Congresso Nacional.

CORDEIRO, J.S. (1993) O problema dos lodos gerados em decantadores de estações de tratamento de águas. Tese (Doutorado) - Escola de Engenharia de São Carlos, Universidade de São Paulo, São Carlos, 342 p.

CORDEIRO, J.S. (2001) Gerenciamento Integrado de Resíduos de Estações de Tratamento de Águas. Anais... $20^{\circ}$ Congresso Brasileiro de Engenharia Sanitária e Ambiental, ABES, cd, I - 062.

CORNWELL, D.A.; MUTTER, R.N.; VANDERMEYDEN, C. (2000) Commercial Application and Marketing of Water Plant Residuals. Denver: American Water Works Association.

DENTEL, S.K. (1997) Evaluation and role rheological in sludge management. Water Science and Technology, v. 36, n. 11, p. 1-8.

IE/SP - Instituto de Engenharia de São Paulo. (2008) Relatório de Conclusões do Seminário Nacional sobre Tratamento, Disposição e Usos Benéficos de Lodos de Estações de Tratamento de Água. In: Seminário Nacional sobre Tratamento, Disposição e Usos Benéficos de Lodos de Estações de Tratamento de Água, São Paulo, IE, 11 p.

ISO - International Organization for Standardization. (2007a) ISO 24510. Activities relating to drinking water and wastewater services: guidelines for the assessment and for the improvement for the service to users. ISO TC 224, $62 \mathrm{p}$

ISO - International Organization for Standardization. (2007b) ISO 24511. Activities relating to drinking water and wastewater service: guidelines for the management of wastewater utilities and for the assessment of wastewater services. ISO TC 224, 59 p.

ISO - International Organization for Standardization. (2007c) ISO 24512. Activities relating to drinking water and wastewater services: guidelines for the management of drinking water utilities and for the assessment of drinking water services. ISO TC 224, 54 p.
ISO - International Organization for Standardization. (2007d) ISO TC 224 - International Organization for Standardization, Technical Committee 224. Disponível em <http://www.iso.org/iso/standards development/ technical_committees/list of iso technical_committees/iso technical committee.htm?commid=299764 > . Acesso em: 17 ago. 2011.

MINISTÉRIO PÚBLICO DO ESTADO DE MINAS GERAIS. (2009) Parecer Técnico - Ref.: Ofício 1139/2008 (CAO-MA) - Informações técnicas referentes aos danos ambientais decorrentes do lançamento de lodo in natura, pelas Estações de Tratamento de Água, no ambiente. Belo Horizonte: Procuradoria-Geral de Justiça, 32 p.

MORITA, D.M; SAMPAIO, A.O.; MIKI, M.K.; DAVID, A.C. (2002) Incorporação de Lodos de Estações de Tratamento de Água em Blocos Cerâmicos. Revista SANEAS, v. 14, p. 7-12. São Paulo.

REALI, M.A.P. (1999) Noções gerais de tratamento e disposição final de lodos de estações de tratamento de água. Projeto PROSAB. Rio de Janeiro: Abes, $250 \mathrm{p}$.

PCJ. (2011) Oficina de lançamento dos resultados da $1^{\circ}$ Etapa. Estudo de viabilidade para instalação e operação de centrais de lodos nas Bacias PCJ. Consórcio das Bacias Hidrográficas PCJ - Piracicaba, Capivari e Jundiaí, 7 p. Disponível em <http://www.agua.org.br/apresentacaoarquivos. aspx?id=73>. Acesso em: 27 fev. 2012.

SIMPSON, A.; BURGESS, P.; COLEMAN, S.J. (2002) The Management of Potable Water Treatment Sludge: Present Situation in the UK. In: Management of Wastes from Drinking Water Treatment. Proceedings. London: The Chartered Institution of Water and Environmental Management, p. 29-36.

SLATTER, P.T. (1997) The Rheological Characterization of Sludges. Water Science and Technology, v. 36, n. 11, p. 9-18.

VIEIRA, P.; ROSA, M.J.; ALEGRE, H.; RAMALHO, P.; SILVA, C. (2009) Avaliação de desempenho de estações de tratamento de água. Revista Água \& Resíduos - Associação Portuguesa de Engenharia Sanitária e Ambiental - APESB, série III, nº 9, p. 4-17. 